\title{
Evaluation of police work of prevention: building an index police management based on the analysis threshold
}

\begin{abstract}
In the provincial police of Argentina's assessment of prevention of police work it is based entirely responsible for the task, leaving aside the study of the situation favoring or not the outcome. This makes indicators that were not designed for this type of policing is used. This paper seeks to open discussion and start thinking about indicators that measure the situation achieved regardless responsible. As a starting point comes the Police Management Index. This methodology adopts threshold analysis presented by the International Association of Crime Analysts assess whether to seek preventive actions implemented by a police unit in an area have been effective or require the joint work of other government departments.
\end{abstract}

Keywords: police management, measurement of policing prevention
Volume I Issue 3 - 2015

Ariel Andres Chelini

Criminal Analyst, Santa Fe Police Department, Argentina

Correspondence: Ariel Andres Chelini, Criminal Analyst, Santa Fe Police Department, 3836 Juan Bautista Alberdi St, Santa Fe city, Province of Santa Fe, Argentina, Tel 0054034215476 1042, Email arielachelini@gmail.com

Received: October 10, 2015 | Published: October 30, 2015

\section{Introduction}

The complexity of the social environment, the changes generated during the last decades of the twentieth century in the forms of thinking about security and the emergence of new information technologies requires the institutions responsible for providing security to base their operational decisions considering a set of techniques and theories that are able to optimize the efficiency demonstrated in the work of prevention of criminal events. The study requires knowledge of the operations and policies adopted by the police force in relation to the organization of personnel, equipment and geographical and temporal distribution of resources. Historically, in institutions such as the provincial police of Argentina, the study of the efficiency of police operations and the policies adopted towards prevention depended exclusively basic statistical information. This information is generated in compliance with the organic command where the biggest problem is highlighted when the work is facing the Napoleonic character that has the police force. The Napoleonic model is the model that traditionally prevailed between the police forces of Latin America. It is militarized and spread throughout the territory. It is also based on the idea of reactive police model, associated with the repression of crime and the maintenance of order. ${ }^{1}$ This model that responds to the logic of peace rather than the citizen security has led to growing insecurity and distrust in the police action among the residents of the neighbourhoods that make up the Argentine cities. Public safety is a broad concept that seeks to satisfy the demands of citizens, obtaining it through the support of the community and local, provincial and national authorities. ${ }^{1}$ Traditionally, these policemen carry out the assessment of their actions considering only the cumulative frequency of complaints received from a police unit located within a neighbourhood. The items to be supplied to the areas of analysis are similar to those in the Criminal Code (robbery, theft, etc.) and are used to estimate the share of these in total units responding to a city or region. A study in 2013 on complaints received by the police unit located in the Guadalupe neighbourhood in the city of Santa Fe, Argentina, during the period from 2011 to 2013 showed the low reliability in assessing traditionally faced. In the year 2012, compared with the previous year, theft residences had grown by 41 percent while stealing people who went walking down the street did 11.5percent. 2013 residential robberies showed a decrease of 133 percent and robberies to people who went walking down the street came down, too, by 143percent. Beyond these encouraging statistics, the problem was observed when for the same period a portion of the neighbours gathered outside the gates of the police station asking for more security and increased presence of troops on the streets Table 1.

Table I Accumulated over the six crime events reported in the Guadalupe neighbourhood in the city of Santa Fe, Argentina.

\begin{tabular}{|c|c|c|c|c|c|}
\hline Objective/Year & 2013 & 2012 & Difference \% 12-13 & 2011 & Difference \% II-I 2 \\
\hline Residential Burglary & 66 & 154 & -1.33 & 90 & 0.42 \\
\hline Shops Robbery & 17 & 48 & -1.82 & 26 & 0.46 \\
\hline Stealing from People in the Street & 54 & $|3|$ & -1.43 & 116 & 0.115 \\
\hline Theft Inside the Car & 11 & 44 & -3 & 28 & 0.36 \\
\hline Motorcycle Theft & 1 & 3 & -2 & 42 & -13 \\
\hline Taxi driver Robbery & 4 & 8 & -1 & 7 & 0.13 \\
\hline Total & 153 & 388 & -1.54 & 309 & 0.2 \\
\hline
\end{tabular}


The purpose is to propose a tool to support the analysis to assess the situation and not the responsible for providing preventive policing. Taking into account the study of police operations carried out in the field, the policies adopted to carry out the activity and to recognize, too, that the police service is an element that has the state to prevent crime. All it based on the concept of public safety and in order to optimize and improve the effectiveness of the actions carried out on the spot.

\section{Materials and methods}

\section{Operations analysis and management analysis}

The International Association of Crime Analysts ${ }^{2}$ indicates that "the criminal analysis describes the techniques and procedures used to study trends and crime patterns, the way it affects a specific jurisdiction and how the police respond to them". Crime analysis does not end with information and turn it into intelligence to assist in decision making but also brings with it the evaluation of the results obtained by the interventions being carried out by those responsible for providing security. Among the functions described by different authors, analysis of operations and management analysis provide answers to how it manages and organizes the police to fulfill their tasks of prevention and well to the results of the investigations are reported. So the aggregation of data needed to carry out these types of analysis is much higher than that required for other types, for example, the tactical, strategic analysis or research. The operations analysis is the study of the operations and policies adopted by the police force to prevent crime. Answers to issues related to optimizing the distribution of police personnel and resources shifts and geographic areas, and also with the efficiency achieved by the interventions carried out in these geographical and temporal spaces. The administrative analysis relates to the presentation of the findings because of the work done in an area; It is presenting them to decision-makers on security, political management and citizens of a geographic area. Follows a process of selection of the most important findings detected in previous analyzes and search submission format best suited for the audience to which it is addressed. The sharing of intelligence society achieved shows both supporters and opponents. Many authors have thought that the decision to disclose the result of analysis developed for a geographic area allows, among other things, increase the level of cooperation of citizens to the police. It also recognizes the right of citizens to know to what degree the crime is a problem in the place where he lives and what are the reasons that those responsible for providing security act the way they do are. Unfortunately, in Argentina it is not possible for citizens to access criminal information; allowing confidence in the police force is severely affected.

\section{Efficiency in police work}

Speaking of efficiency in police work involves observing how far the institution is effective in preventing and controlling the risk factors, over which it has influence, encouraging the emergence of criminal events. Of course, that when talking about risk factors need to understand that it requires a multidisciplinary and multiagency the problem seen in an area approach, so it is a task that is fraught with difficulties. Something similar happens when the cost involved in the work of the police is evaluated. Ignacio $\mathrm{Cano}^{3}$ states that if a policeman is not effective in providing its service to the community there is no question of efficiency in the way it operates because the discussion is confined only to the cost paid by the government the safety concept. This could force the police institution to achieve effectiveness at any cost, generating exclusion as a result of the evaluation study of the preventive work done. Speaking of costs in the measurement of police work suggests the traditional idea of security that you feel its foundations in the suppression of crime and maintaining public order.

The first exception that should be taken into account in any assessment is that police may lie in three different areas:

\section{The individual performance of each police}

II. The impact on society of a new program of police work

\section{Quality of the police organization as a whole.}

In our case, the quality of the police organization is the context in which this document focuses; as sub-purpose sought to achieve a situation monitoring pre and post intervention on risk factors having influence policing. The intended purpose is important not only because it helps in the decision to choose indicators for evaluation, but also determines the attitude of the institution to the assessment.

Thus, in a police force that responds to the idea of security located in an exclusive environment and crime control reactive and repressive nature, the practical implications of the assessment may influence the way the criminal information originating spreads within of the organization. An institution such as the Santa Fe police often is evaluated according to the cases investigated, usually recorded fewer criminal events that cannot be solved in this way (eg, the absence of registration in the case of theft a low amount of cash to a person moving on foot through the streets). While it is indisputable that any assessment must be based on a reliable and consistent information, the reality shows that the perception of police personnel on the "why" of the assessment influences the validity and consistency of the information received, necessitating the addition of other sources to gauge the risks to public safety that is observed in an area. Victimization surveys and polls carried out in persons apprehended shown as best placed to complete the knowledge of the criminal reality in an area of the city. Now, speaking of police work involves aware that a police, such as the province of Santa $\mathrm{Fe}$, has two functions (to prevent and investigate) within a whole that is providing security services to the community. Prevention and research, but can be conceptualized differently from the theory, in practice the distinction is very diffuse and prevents, in most cases, reach an agreement on how to evaluate them. This is related to wanting to assess police work according to results obtained by intervention or by the police effort made to achieve these results. Is clear that the public is interested in the impact of police action on insecurity to know the effort made to achieve more, reality shows, according to Bailey, ${ }^{4}$ the safety of people is dependent on many factors that they are beyond the reach of the police. "The myth that any safety problem is the result of a bad police and that could be solved by a good cop is just that, a recurring myth that still populate the consciences of many people and the electoral programs of some candidates". ${ }^{3}$ Evaluate the police as the result is wrong because it involves them responsible for items that are out of your control. The question lies in how we evaluate police actions in response to this new element and the answer is to think of a methodology to isolate the effects of the observed problem that caused the task to conduct the police in place and how they were raised before the intervention of the institution. That explains why the application of some indicators that reflect policing mistrust in the citizen and experts when the results obtained by the police in an area. For example, the increase in the number of arrests practiced in an area or seized items can be seen as a better performance of police work or an increase in crime that plagues 
the place. Something similar happens in applying these indicators to prevention activity because these actions may not have the desired increased safety impact. This issue was addressed in the research conducted by Spehan et al., ${ }^{5}$ in Kansas City (USA) between 1972 to 1973 which showed that an increase in random patrol does not reduce crime and the perception of insecurity or improvements 911 service does not increase the likelihood of catching the offender. Another element behind when considering the task of police assessment is the availability of information from actors outside the institution. These elements, which take the lead as above, is very close to the concept of reliability and integrity of information, generates subjective evaluations that prevent a better understanding of the criminal reality observed and encourage efficiency analysis without taking into account the effectiveness of the work done by the institution.

The idea of taking the criminal information as a state secret, where a single component parts that are part of the public security system is responsible for the collection and dissemination of information for decision-making, promotes citizenship in one poor perception of the actions of the justice system and the police, directly affecting the assessment of police work before and after the problem is identified. This issue fuels the difference between the number of all crimes committed in a time and a place and those that are recorded by information systems. The so called black figure is also a major impediment to assessing the integrity of information because it depends on various factors such as not reporting crimes, for the victim, not worth communicating (the lower the gravity Crime suffered the biggest victim is the sub record), distrust of the people in the justice system (if the police and the courts are seen by victims as inefficient or corrupt, the higher the index that records the black figure) or the discretion of the police personnel when allegations avoid making only minor events decanted into bureaucratic work without judgment. Another factor that influences the valuation of police action within a particular space-territory is the preparation of standardized indicators or approved international data. It is common to see comparisons and reports where numbers of robberies, thefts, murders, suicides occur, etc. per 10,000 inhabitants, of arrests, searches conducted and of confiscated items, among others. Focus assessment on such data confronts us with three problems:

I. As mentioned above, fails to remove the criminal phenomenon responsibility that lies with the police as one of the parts needed to prevent the occurrence of risk factors;

II. These data types are a general tool that fail to identify what actually happens on the spot;

III. as already mentioned, depend excessively on the criteria that the police themselves may alter due to their own activities or for other reasons.

\section{Police management index}

The document aims to create and display an indicator of police management that takes into account the factors that favor the commission of the crime in an area. The idea is to evaluate objectively the policing prevention that develops at the site. If this managed to modify them or, if not have, if the ineffectiveness is due to the emergence of new elements or the existence of components that determine the reliability of the data we have for evaluation. The indicator is defined adopting the threshold analysis presented by IACA and developed by Christopher W Bruce. ${ }^{6}$ The Police Management Index (IGP) is a statistical tool that evaluates the performance achieved by a police unit in the prevention of a criminal event during a calendar month and compared with the average achieved by the same unit in the last four years. Note that talking about the event and not a crime broadly as typified in the Criminal Code because it seeks to assess the effectiveness of the actions of prevention, taking into account the characteristics presented the event which sought to intervene in place. Also, while it is clear that the indicator fails to identify risk factors that cannot be prevented by police action, it must be remembered that this tool allows the analyst to have the opportunity to identify the influence they have on the Final results of the intervention. The external risk factors to policing are, among others, socioeconomic status, culture, education, geographic location and characteristics of urbanization. Also, the calendar month when compared to the average of the last four years, bias resulting from the use of only information issued by the police is reduced. Also achieve eradicate the idea of preventing based on the Criminal Code rather than modify the elements that make fosters the generation of crime. The IGP, like Threshold Analysis is calculated from data collected on criminal events that are reported to the police authority in the geographical area where it is applied. In your application you can join panels of information gathered neighbours and victimization surveys. The purpose is to reduce the effect of underreporting influencing the preparation of the indicator. As in the construction of the threshold, the IGP requires historical data bases, at least 3years. Although, as Bruce said, the calculation can be applied to any data range (from a day to a full year) is better to limit queries to periods of time divisible by seven. The index construction and analysis of results are displayed with the theft to people over 60 who move on foot through the streets of Guadalupe neighbourhood. Simulated data for the month of August of 2009, 2010, 2011 and 2012 and compared to 2013. Table 2.

Table 2 Robbery people over 60years occurred in the street. Guadalupe neighbourhood, Santa Fe, Argentina.

\begin{tabular}{ll}
\hline Year & Total August \\
\hline 2009 & 8 \\
2010 & 13 \\
2011 & 20 \\
2012 & 12 \\
2013 & 23
\end{tabular}

The IGP begins by calculating the expected number for each event in a calendar month. This is achieved by calculating the average of the monthly events accumulated during the last four years $(2009,2010$, 2011 and 2012).

$$
\bar{x}=\frac{8+13+20+12}{4}=13.25
$$

Formula 1: Expected amount of theft from people over 60 years occurred in public during the month of August. Guadalupe neighbourhood, Santa Fe city, Argentina.

Reached the normal value for the month being analyzed, the indicator requires knowing how much data moved from the expected events for that time span value. The response is achieved by calculating the standard deviation of the mean. Formula 2 shows the calculation of the deviation from the mean of the data related to the event of theft to people over 60 years occurred in public during the month of August. 


$$
\sigma=\sqrt{\frac{\left((8-13.25)^{2}+(13-13.25)^{2}+(20-13.25)^{2}+(12-13.25)^{2}\right)}{4}}
$$

$$
\sqrt{\frac{(27,56+0,0625+45,56+1,56)}{4}}=\sqrt{\frac{74,745}{4}}=\sqrt{18,69}
$$

$$
\sigma=4,323
$$

Formula 2: Standard deviation for robberies to people over 60 years occurred in the street in August. Guadalupe Neighbourhood, Santa Fe city, Argentina.

Known as the data have moved relative to the mean, the next step is to establish that ranges between can expect that the amounts appear in most years during the same month. This information is obtained by subtracting or adding one standard deviation to the average obtained in the first step.
Minimum range $=13 \cdot 25-4 \cdot 323=8,927=9$

Maximum range $=13.25+4.323=17,573=17$

We expect the amount of theft events for people over 60 years occurred in the street during August is located between 9 and 17. Finally, the indicator gets one more fact: the standard score. The standard score identifies how far the average value obtained for our case, August 2013, for the event of theft to people over 60 years occurred on the street is. This is obtained by subtracting a month being assessed the average obtained in the first step, and then divides the product by the standard deviation calculated.

$$
z=\frac{23-13.25}{4.323}=2.25
$$

With the data, the frequency table shows the event of theft for people over 60 took place in public in the month of August and in the neighbourhood Guadalupe neighbourhood in Santa Fe city, Argentina Table 3.

Table 3 Robbery people over 60 years in the street in August.

\begin{tabular}{llllllllll}
\hline Month/Year & 2009 & $\mathbf{2 0 1 0}$ & $\mathbf{2 0 1 1}$ & $\mathbf{2 0 1 2}$ & Average & Standard deviation & Range & $\mathbf{2 0 1 3}$ & $\mathbf{Z}$ \\
\hline August & 8 & 13 & 20 & 12 & 13.25 & 4.323 & Sep-17 & 23 & 2.25 \\
\hline
\end{tabular}

Source: data simulated for the document.

The standard interpretation obtained for the indicator differs from the interpretation given to it in the threshold analysis. So, considering that by definition standards scores move between the values -2 and +2 ; the product obtained is interpreted as follows:

I. $Z=0$ : The police action carried out in the district has failed to modify the risk factors that are the responsibility of the institution to attend.

II. $Z$ between 0 and +1 : The incorporation of new factors that might be favoring the commission of criminal events observed at the site. Also, the observation might be due to the displacement of crime in the area. We recommend starting the tort study of these to achieve from the police identifies and act accordingly.

III. $\mathrm{Z}$ between +1 and +2 : The influence of new factors that facilitate the commission of crime is confirmed. The creation of a public safety committee made up of the various government agencies and the residents themselves, who can respond to the problem and its causes multidirectional, transversal and multicausal manner recommended.

IV. $\mathrm{Z}$ between 0 and -1 : It shows good police performance in the task of preventing the risk factors that can handle the department.

V. Z between -1 and -2 : A great influence of the elements that determine the reliability of the data included in the indicator is observed. This can cause a strong impact on data records or sub criteria established by the police department at the time of reporting data.

External factors influencing the outcome of the IGP (both positive and negative) are unable to be identified by the indicator. This only shows the ultimate need to call different areas of government in order to evaluate and identify the factors that influence the crime (e.g., socioeconomic status, culture, development of the site, etc.)

\section{Discussion}

Apply the indicator means giving a possible answer to how to assess prevention activities carried out by the police. Thus, this evaluation tool excludes not only the indicators designed exclusively for the research activity, but also the use of general information that says little about the criminal reality observed. He no longer talks about crime as classified in the Penal Code, and passed to understand the event as a social phenomenon with specific characteristics provided by the place where it occurs. The same applies to one of the problems affecting the assessment: the reliability of data used when assembling an indicator. Using a collection of historical data, the indicator aims to make use of the law of large numbers to reduce the effect caused by the attitude that can make the police force when assessed in their work known. While it is clear that the indicator fails to identify the risk factors that cause the tort phenomenon, also it managed to decrease the influence of these in the equation. Showing, according to the standard value it approximates +2 , which operate in place elements that are beyond the policing and demanding approach the problem from a multicausal, multi-disciplinary and multi-agency perspective. Moreover, proper use dilutes the idea of taking only information that originates in the institution itself and includes information panel's neighbours and victimization surveys, assuming a feedback focused on the idea of public safety rather than security public. Thus, the indicator eradicated the concept of "state secret" that is intended to give the criminal information, promoting awareness of the public about what is really happening in the place where he lives. Improving, with this action, not only the perception of the neighbour to the institution, but also the effectiveness of the proposed actions. The indicator goes beyond the simple observation that can be achieved by reading the area for what is "expected" in the occurrence of a particular event to enter the evaluation of reality that has nothing to do with the simple accumulation data reported. Thus, the percentage of variation ( $\mathrm{Z}$ value) becomes relevant at the conclusion of the analysis. 


\section{Acknowledgments}

None.

\section{Conflicts of interest}

The author declares that there are no conflicts of interest.

\section{References}

1. Barrios Miguel Ángel. Citizen security from the municipal to the continental. In: Biblos Buenos Aires, editors. Argentina. 2013.

2. International Association of Crime Analysts. Frequently asked questions. 2014.
3. Ignacio Cano. The police and their evaluation. Proposals for the construction of evaluation indicators in police work. Center for Development Studies. Santiago, Chile. 1996.

4. Bailey DH. Measuring Overall Effectiveness, Quantifying Quality in Policing. Executive Research Forum Police, Washington, USA. 1996;37-54.

5. Spelman W, Brown D. Calling the police: Citizen reporting of Serious Crime. Police Executive Research Forum, USA. 1981;612.

6. Bruce Christopher W. The threshold analysis. Procedures for the analysis and reduction of crime. Ed. Citizen Peace Foundation. Santiago, Chile. $2012 ; 88$.

7. Aparicio Julio Enrique. Society and crime. In: Lumen, editor. Argentina. $2011 ; 243$. 